Changes in persistence, spurious regressions and the Fisher hypothesis

\author{
Robinson Kruse, Daniel Ventosa-Santaulària \\ and Antonio E. Noriega
}

CREATES Research Paper 2013-11 


\title{
Changes in persistence, spurious regressions and the Fisher hypothesis *
}

\author{
Robinson Kruse \\ Daniel Ventosa-Santaulària \\ Antonio E. Noriega ${ }^{\S}$
}

April 16, 2013

\begin{abstract}
Declining inflation persistence has been documented in numerous studies. When such series are analyzed in a regression framework in conjunction with other persistent time series, spurious regressions are likely to occur. We propose to use the coefficient of determination $R^{2}$ as a test statistic to distinguish between spurious and genuine regressions in situations where time series possibly (but not necessarily) exhibit changes in persistence. To this end, we establish some limit theory for the $R^{2}$ statistic and conduct a Monte Carlo study where we investigate its finite-sample properties. Finally, we apply the test to the Fisher equation for the U.S. and Mexico. Contrary to a rejection using cointegration techniques, the $R^{2}$-based test offers strong evidence favourable to the Fisher hypothesis.
\end{abstract}

Key Words: Changes in persistence, Spurious regression, Fisher hypothesis.

JEL classification: C12, C22, E31, E43

\section{Introduction}

Structural breaks in autoregressive models have been studied widely, see Perron (2006) for a comprehensive survey on the recent developments in this field. A special kind of a structural break is a change in

*Participants at the 20th Annual Symposium of the Society for Nonlinear Dynamics and Econometrics in Istanbul, Turkey and at the Statistical Week 2012 in Vienna, Austria provided useful comments. Moreover, the authors thank Matei Demetrescu and Michael Massmann for helpful discussions on an earlier draft of the paper. Part of this research was carried out while the second author was visiting CREATES at Aarhus University, Denmark; their kind hospitality is greatly appreciated. Robinson Kruse gratefully acknowledges support from CREATES - Center for Research in Econometric Analysis of Time Series (DNRF78), funded by the Danish National Research Foundation.

${ }^{\dagger}$ Leibniz University Hannover [School of Economics and Management, Institute of Statistics, Königsworther Platz 1, D30167 Hannover, Germany] and CREATES, Aarhus University [Department of Economics and Business, Fuglesangs Allé 4, DK-8210 Aarhus V, Denmark. E-mail: rkruse@creates.au.dk.]

¥Centro de Investigación y Docencia Económicas, CIDE [Carretera México-Toluca 3655, Col. Lomas de Sta Fe, Del. Álvaro Obregón, México D.F, C.P. 01210. E-mail address: danieleventosa-santaularia.com ]

${ }^{\S}$ Banco de México [Dirección General de Emisión, Legaria 691, Col. irrigación, México D.F., México. E-mail address: anoriega@banxico.org.mx] and Universidad de Guanajuato [Department of Economics and Finance, Cerro El Establo S/N, Guanajuato, Gto. México.] 
persistence. It is characterized by a change in the order of integration of a time series. For instance, a first-order autoregressive (AR) model exhibits a change in persistence if the AR parameter equals one during the pre-break sample and less than unity (in absolute value) after the breakpoint. Persistence declines in the sense that the process switches from being $I(1)$ to $I(0)$. Main contributions to this topic are Kim (2000), Leybourne, Kim, Smith, and Newbold (2003), Busetti and Taylor (2004), Kurozumi (2005), Harvey, Leybourne, and Taylor (2006), Leybourne, Kim, and Taylor (2007) and Leybourne, Taylor, and Kim (2007) inter alia. As Perron (2006) points out, changing persistence has been an important feature of economic time series. In particular, inflation rates are typically found to display declines in persistence, see e.g. O'Reilly and Whelan (2005), Kumar and Okimoto (2007), Halunga, Osborn, and Sensier (2008), Noriega and Ramos-Francia (2009), Kang, Kim, and Morley (2009), Kejriwal (2012) and Kouretas and Wohar (2012). It is a natural approach to investigate the consequences of changing persistence in a regression framework, which has not been conducted yet (at least to our best knowledge). Important regressions involving inflation series are the Fisher equation, Taylor rules and the Phillips curve amongst others. Asymptotic theory is well known and established for the case of stable persistence, but there is a lack of it when it comes to structural changes in the persistence of time series.

This paper studies the asymptotic properties of standard regression techniques under changes in persistence. It turns out that the problem of spurious regressions becomes important. Spurious regressions have been considered, since its reappraisal in Granger and Newbold (1974), as a pervasive problem in time series econometrics. It occurs when "[...] a pair of independent series, but with strong temporal properties, is found apparently related according to standard inference [...] [t' The theoretical framework provided by Phillips (1986) explained the phenomenon using non-standard asymptotics. Spurious regression may indeed occur under a wide array of data generating processes, whether these are stationary or not: driftless unit roots (Phillips 1986), higher-order integrated processes (Marmol 1995, Marmol 1996)], unit root with drifts (Entorf 1997), stationary processes (Granger, Hyung, and Jeon 2001), long-memory processes, stationary or not (Marmol 1998, Tsay and Chung 2000), trend stationary processes, with and without breaks and combinations thereof 2

Our large-sample results show that the estimation of regression models can lead to spurious inference when at least one of the variables possesses a change in persistence. Indeed, the $t$-ratios associated to the estimates diverge, whether the variables are truly linearly related or not; such a result is quite intuitive. Nevertheless, our results also provide a clear suggestion for testing whether the relationship is spurious or meaningful. This paper proposes the coefficient of determination $R^{2}$ as a test statistic. It is shown that the $R^{2}$ exhibits a non-standard limit distribution depending on the unknown breakpoints when no relation between the variables exists. Under the alternative hypothesis of a meaningful linear relationship, the $R^{2}$ converges to unity. Critical values of the $R^{2}$ statistic are obtained via simulations. Empirical size and power properties of the test are investigated in a Monte Carlo study. It appears that the test performs well under a relatively vast array of alternative DGPs and situations.

\footnotetext{
${ }^{1}$ Granger, Hyung, and Jeon (2001).

${ }^{2}$ See Noriega and Ventosa-Santaulària (2007). A brief survey of the literature concerning spurious regression can be found in Ventosa-Santaulària (2009).
} 
As an empirical application, we study the Fisher equation for Mexico and the United States. While standard econometric tools like cointegration analysis do not lead to supportive results, the situation is different when applying the $R^{2}$ test: We find strong evidence for the empirical validity of the Fisher effect. Our approach is related to many previous studies in this field. Most of them consider unit root tests, cointegration techniques and structural breaks. Our study complements the literature by considering the consequences of changing inflation persistence for testing the Fisher effect as a novelty. Importantly, we propose a simple OLS regression-based test for the Fisher hypothesis which is a long standing issue in monetary economics. In direct connection, the persistence properties of inflation and nominal (and real) interest rates are analyzed.

An important early contribution is Barsky (1987), who studies the effect of changing inflation persistence in relation to the Fisher hypothesis and forecastability of inflation 3 Koustas and Serletis (1999) apply unit root and stationarity tests to inflation and interest rates and test for cointegration amongst these variables in order to test for the Fisherian link. Rapach and Weber (2004) re-examine and extend a study by Rose (1988) by using advanced unit root and cointegration techniques. Lanne (2006) suggests a nonlinear bivariate mixture autoregressive model for interest rates and inflation. A nonlinear cointegration approach is taken by Christopoulos and León-Ledesma (2007). Panel cointegration methods for testing the Fisher hypothesis are proposed in Westerlund (2008). Recently, Tsong and Lee (2013) apply quantile cointegration methods. Jensen (2009) investigates the consequences of fractionally integrated processes for tests of the Fisher hypothesis. Structural breaks in deterministic terms (i.e. intercept and trend) in relation to the Fisher effect are studied in Malliaropulos (2000), Rapach and Wohar (2005), Lai (2008) and Haug, Beyer, and Dewald (2011). A Markov switching analysis of the US real interest rate has been put forward by Garcia and Perron (1996). These studies underline the importance of integration orders and structural breaks for testing the Fisher hypothesis.

The remaining body of the paper is organized as follows. Section 2 presents the setup and the asymptotic results together with simulated critical values. In Section 3, the Monte Carlo simulation study is described and results are presented. Empirical applications are given in Section 4. Finally, conclusions are drawn in Section 5. Mathematical proofs are provided in the Appendix.

\section{Setup and asymptotic results}

This article reconsiders the problem of spurious regressions in a bivariate setup were variables $(y, x)$ are allowed to exhibit a single structural break in their order of integration. The focus lies on the bivariate setup to illustrate the problem and the suggested testing procedure. Clearly, the methodology can be extended to multiple regressors without further complications. We study the asymptotic behaviour of OLS estimation and inference under a variety of possible situations. If changes in persistence are neglected, spurious regressions are likely to occur. By $I(1 / 0)$, we denote a variable that exhibits a decline in persistence at some breakpoint $\lambda$. The case of increasing persistence, i.e. $I(0 / 1)$, is treated analogously. We analyze

\footnotetext{
${ }^{3}$ A detailed survey is provided by Neely and Rapach (2008).
} 


\begin{tabular}{|c|c|c|c|}
\hline Case & DGP for $y$ & DGP for $x$ & Remarks \\
\hline \multicolumn{4}{|c|}{$y, x$ are independent } \\
\hline M1 & $I(1)$ & $I(1)$ & Both series are constant $I(1)$ processes \\
\hline M2 & $I(1 / 0)$ & $I(1)$ & $y$ exhibits a decline in persistence, $x$ is a constant $I(1)$ process \\
\hline M3 & $I(1)$ & $I(1 / 0)$ & $y$ is a constant $I(1)$ process, $x$ exhibits a decline in persistence \\
\hline M4 & $I(1 / 0)$ & $I(1 / 0)$ & Both series exhibit a decline in persistence at the same breakpoint \\
\hline M4' & $I(1 / 0)$ & $I(1 / 0)$ & Both series exhibit a decline in persistence at different breakpoints \\
\hline M5 & $I(d)$ & $I(d)$ & Both series are fractionally integrated (of the same order) \\
\hline M5' & $I\left(d_{y}\right)$ & $I\left(d_{x}\right)$ & Both series are fractionally integrated (of different orders) \\
\hline \multicolumn{4}{|c|}{$y, x$ are dependent } \\
\hline M6 & $I(1)$ & $I(1)$ & Both series are cointegrated, no change in persistence occurs \\
\hline M7 & $I(1 / 0)$ & $I(1 / 0)$ & Both series are first cointegrated, then related (after the breakpoint) \\
\hline
\end{tabular}

Table 1: Data Generating Processes.

seven relevant data generating processes, see Table 1.

For M1, both, $y_{t}$ and $x_{t}$ are independent $I(1)$ processes. In M2, $y_{t}$ exhibits a reduction in persistence from $I(1)$ to $I(0)$ at $\left[\lambda_{y} T\right]$ ( $[a]$ denotes the nearest integer of $a$ ), while $x_{t}$ is $I(1)$ throughout the sample; $y_{t}$ and $x_{t}$ are independent of each other. M3 is similar to M2, but the roles of $y_{t}$ and $x_{t}$ are reversed. In M4, both, $y_{t}$ and $x_{t}$ exhibit a decline in persistence from $I(1)$ to $I(0)$ at $\left[\lambda_{y} T\right]=\left[\lambda_{x} T\right]$, respectively. The breakpoints $\lambda_{y}$ and $\lambda_{x}$ are allowed to be different (M4'). Regarding M5, $y_{t}$ and $x_{t}$ are independent fractionally integrated $I(d)$ processes. The order of fractional integration is the same, while the opposite is true in M5'. Turning to the DGPs where spurious regressions do not occur, we first consider M6: Both, $y_{t}$ and $x_{t}$ are constant $I(1)$ processes and they are cointegrated. This is a standard case studied intensively in the related literature. In M7, $y_{t}$ and $x_{t}$ exhibit declines in persistence at the same point in time, but not necessarily to the same level of persistence., i.e. autoregressive parameters are allowed to differ after the breakpoint. They are cointegrated in the first sub-sample and correlated in the second. The cases of increasing persistence are analogous and not reported to conserve space ${ }^{4}$

The considered (predictive) regression model is given by

$$
y_{t+1}=\alpha+\beta x_{t}+u_{t+1} \text {. }
$$

It also possible to consider the contemporaneous model: $y_{t}=\alpha+\beta x_{t}+u_{t}$ without any complication. We focus on the first specification as it is in line with the Fisher equation which serves as our empirical application. For simplicity, we consider the following DGP for the regressor $x_{t}$,

$$
x_{t}=\delta(1-\phi)+\phi x_{t-1}+v_{t},
$$

where $\phi=1$ for $t=1,2, \ldots,\left[\lambda_{x} T\right]$ and $|\phi|<1$ for $t=\left[\lambda_{x} T\right]+1, \ldots, T$ with $\lambda_{x} \in[0,1]$. When $0<\lambda_{x}<1$ (relevant for M3, M4, M4', and M7; see Table 1), the process has a change in persistence: it starts as an

\footnotetext{
${ }^{4}$ Full results are available from the authors upon request.
} 
$I(1)$ process at the beginning of the sample and becomes $I(0)$ after the breakpoint. When $\lambda_{x}=1$ (relevant for M1, M2, and M6), there is no change in persistence and the process behaves as a random walk along the whole sample. As for the DGP of $y_{t}$, we envisage two informative alternatives:

1. The process is independent of $x_{t}$ and in particular,

$$
y_{t+1}=\mu(1-\rho)+\rho y_{t}+e_{t+1}
$$

where $\rho=1$ for $t=1,2, \ldots,\left[\lambda_{y} T\right]$ and $|\rho|<1$ for $t=\left[\lambda_{y} T\right]+1, \ldots, T ; \lambda_{y} \in[0,1]$. The persistence properties are analogous to the ones discussed for the regressor $x_{t}$ above.

2. The variables are allowed to be linearly related to each other. In this case, the DGP of $y_{t}$ corresponds to equation (1). Note that, if $x_{t}$ has a change in persistence in $\left[\lambda_{x} T\right]$, the variables are cointegrated during the period $t=1$ to $t=\left[\lambda_{x} T\right]$. Afterwards, althhough there is not anymore a long-run equilibrium relationship, $x_{t}$ and $y_{t}$ remain correlated (Model M7).

Some remarks on notation are in order. In the following Theorem 1, convergence in distribution is denoted as $\stackrel{D}{\rightarrow}$, and $W_{z}$ is a standard Wiener process, i.e., $W_{z}(r)$ is normally distributed for every $r$ in $[0,1]$; that is $W_{z}(r) \sim \mathcal{N}(0, r)$. To simplify notation, all integrals are understood to be taken with respect to the Lebesgue measure, i.e., integrals such as $\int_{0}^{1} W_{z}, \int_{0}^{1} W_{z}^{2}, \int_{0}^{\lambda} W_{z}$, and $\int_{0}^{\lambda} W_{x} W_{y}$ are short for $\int_{0}^{1} W_{z}(r) d r$, $\int_{0}^{1} W_{z}^{2}(r) d r, \int_{0}^{\lambda} W_{z}(r) d r$, and $\int_{0}^{\lambda} W_{x} W_{y}(r) d r$, respectively $\left.\right|_{5} ^{5}$ As with the properties of $e_{t}$ and $v_{t}$, we assume they satisfy Hamilton's (1994, p. 505) standard assumption, that is:

Assumption 1 Let $z_{t}=\Psi(L) \varepsilon_{z t}=\sum_{j=0}^{\infty} \Psi_{z, j} \varepsilon_{z, t-j}$ for $z=e, v$, where $\sum_{j=0}^{\infty} j\left|\Psi_{z, j}\right|<\infty$ and $\left\{\varepsilon_{z, t}\right\}$ is and i.i.d sequence with mean zero, variance $\sigma_{z}^{2}$, and finite fourth moment.

The derivations in this work hold under more general data generating processes (in particular linear processes with stationary martingale difference innovations), but these assumptions are sufficient to give insight into the behaviour of the coefficient of determination in the case of a possibly spurious regression under changes in persistence.

Theorem 1 Suppose that the regression model (1) is estimated by Ordinary Least Squares (OLS) and that Assumption 1 holds. Then, as $T \rightarrow \infty$ :

(i) When $x_{t}$ and $y_{t}$ are generated as in case $M 2$,

$$
R^{2} \stackrel{D}{\rightarrow} \frac{\left(\int_{0}^{\lambda} W_{x} W_{y}-\int_{0}^{1} W_{x} \int_{0}^{\lambda} W_{y}\right)^{2}}{\Gamma_{1, x} \cdot \Gamma_{\lambda, y}}
$$

(ii) When $x_{t}$ and $y_{t}$ are generated as in case $M 3$,

$$
R^{2} \stackrel{D}{\rightarrow} \frac{\left(\int_{0}^{\lambda} W_{x} W_{y}-\int_{0}^{\lambda} W_{x} \int_{0}^{1} W_{y}\right)^{2}}{\Gamma_{\lambda, x} \cdot \Gamma_{1, y}}
$$

\footnotetext{
${ }^{5}$ Theorem 1 presents exclusively the results needed to build the proposed test. Many other results regarding the asymptotic behavior of the OLS estimators, the t-ratios and the $F$ test are also obtained and are available from the authors upon request.
} 
(iii) When $x_{t}$ and $y_{t}$ are generated as in case M4,

$$
R^{2} \stackrel{D}{\rightarrow} \frac{\left(\int_{0}^{\lambda} W_{x} W_{y}-\int_{0}^{\lambda} W_{x} \int_{0}^{\lambda} W_{y}\right)^{2}}{\Gamma_{\lambda, x} \cdot \Gamma_{\lambda, y}}
$$

(iv) When $x_{t}$ and $y_{t}$ are generated as in case M4',

$$
R^{2} \stackrel{D}{\rightarrow} \frac{\left(\int_{0}^{\lambda_{I}} W_{x} W_{y}-\int_{0}^{\lambda_{I}} W_{x} \int_{0}^{\lambda_{I}} W_{y}\right)^{2}}{\Gamma_{\lambda, x}^{I} \cdot \Gamma_{\lambda, y}^{I}}
$$

(v) When $x_{t}$ and $y_{t}$ are generated as in case M7,

$$
T\left(1-R^{2}\right) \stackrel{D}{\rightarrow} O_{p}(1)
$$

where, $\Gamma_{\gamma, z}=\left(\int_{0}^{\lambda_{z}} W_{z}\right)^{2}-\int_{0}^{\lambda_{z}}\left[W_{z}\right]^{2}$, for $z=y, x ; \lambda=\lambda_{x}=\lambda_{y}$ (cases M1, M2, M3, and M5) and $\lambda_{I}=$ $\min \left(\lambda_{x}, \lambda_{y}\right)$ (case M4)

In an unreported Theorem, it is shown that the $t$-statistics for both independent and cointegrated cases diverge, as could be expected from previous results in the literature ${ }^{6}$ From Theorem 1 , it is clear that the $R^{2}$ can be used to differentiate non-sense regressions from meaningful regressions. When there is a true relationship between the variables, the $R^{2}$ tends to 1 whilst, in any other case, it has a limit distribution according to Theorem 1. Moreover, the asymptotic distribution of the $R^{2}$ has no nuisance parameter except for the relative breakpoint $\lambda$. The limit distribution also depends on the number of series exhibiting a change in persistence (cf. critical values for M2/M3 and M4). This suggests that we can build a test statistic and obtain critical values that depend on the location of the change in persistence. In practice, the application of the test requires estimates of the unknown breakpoints which is discussed in Section 3.

In Table 2, we report asymptotic critical values for the $R^{2}$ statistic at usual nominal significance levels for different cases. These cases are: no change in persistence (M1); only one time series exhibits a change in persistence (M2 and M3); both time series are subject to a change in persistence (M4). In case of a structural break. Critical values are provided in steps of 0.05 from 0.1 to 0.9 for the relative breakpoint $\lambda$. It can be seen that for a given case, critical values for a fixed significance level have a non-monotonic relationship with the breakpoint. In addition, critical values for M2 and M3 are nearly identical as to be expected from Theorem 1. Lastly, critical values are larger the more breaks one considers, i.e. critical values for M4 are larger than those for M2 and M3.

The $R^{2}$ test can also be useful to discriminate between a real linear relationship and a spurious one when the series are stationary and fractionally integrated. Let us consider two cases: (1) say $0<d_{z}<0.5$ for $z=x, y$. In this case, according to Tsay and Chung (2000), the $R^{2}$ is $o_{p}(1)$, so the the test is expected to work even under stationary fractional integration; (2) Suppose now that $0.5<d_{z}<1$ : the usefulness

\footnotetext{
${ }^{6}$ We also studied the case in which $y_{t+1} \sim I(1 / 0)$ and $x_{t} \sim I(1 / 0)$ cointegrate in the first part of the sample but are independent in the second part. In that case, the estimates of $\alpha$ and $\beta$ do not converge to their true value (when the variables cointegrate) and the $t$-ratios also diverge. The results are available upon request.
} 


\begin{tabular}{rrrrrrrrrr}
\hline & & $\mathrm{M} 2$ & & & $\mathrm{M} 3$ & & & $\mathrm{M} 4$ & \\
$\lambda$ & $10 \%$ & $5 \%$ & $1 \%$ & $10 \%$ & $5 \%$ & $1 \%$ & $10 \%$ & $5 \%$ & $1 \%$ \\
\hline 0.10 & 0.174 & 0.230 & 0.342 & 0.172 & 0.237 & 0.36 & 0.538 & 0.635 & 0.757 \\
0.15 & 0.266 & 0.344 & 0.483 & 0.272 & 0.355 & 0.493 & 0.648 & 0.734 & 0.837 \\
0.20 & 0.354 & 0.444 & 0.602 & 0.357 & 0.444 & 0.593 & 0.695 & 0.772 & 0.872 \\
0.25 & 0.412 & 0.510 & 0.642 & 0.416 & 0.509 & 0.653 & 0.721 & 0.797 & 0.886 \\
0.30 & 0.464 & 0.558 & 0.698 & 0.461 & 0.562 & 0.698 & 0.730 & 0.808 & 0.891 \\
0.35 & 0.503 & 0.598 & 0.750 & 0.501 & 0.601 & 0.745 & 0.739 & 0.809 & 0.898 \\
0.40 & 0.532 & 0.637 & 0.761 & 0.532 & 0.631 & 0.764 & 0.727 & 0.808 & 0.896 \\
0.45 & 0.561 & 0.654 & 0.785 & 0.557 & 0.659 & 0.793 & 0.724 & 0.808 & 0.894 \\
0.50 & 0.584 & 0.686 & 0.814 & 0.582 & 0.675 & 0.809 & 0.715 & 0.798 & 0.888 \\
0.55 & 0.598 & 0.691 & 0.819 & 0.590 & 0.688 & 0.807 & 0.707 & 0.785 & 0.884 \\
0.60 & 0.606 & 0.704 & 0.823 & 0.608 & 0.700 & 0.823 & 0.704 & 0.784 & 0.884 \\
0.65 & 0.609 & 0.699 & 0.820 & 0.611 & 0.705 & 0.824 & 0.692 & 0.773 & 0.870 \\
0.70 & 0.617 & 0.712 & 0.831 & 0.623 & 0.720 & 0.838 & 0.679 & 0.768 & 0.871 \\
0.75 & 0.615 & 0.712 & 0.830 & 0.614 & 0.710 & 0.829 & 0.654 & 0.742 & 0.860 \\
0.80 & 0.621 & 0.714 & 0.834 & 0.614 & 0.708 & 0.834 & 0.645 & 0.730 & 0.836 \\
0.85 & 0.610 & 0.709 & 0.825 & 0.611 & 0.706 & 0.825 & 0.627 & 0.722 & 0.835 \\
0.90 & 0.608 & 0.705 & 0.828 & 0.603 & 0.698 & 0.841 & 0.616 & 0.705 & 0.830 \\
\hline & & $\mathrm{M} 1$ & & & & & & & \\
1.00 & 0.601 & 0.694 & 0.827 & & & & & & \\
\hline & & & & & & & & &
\end{tabular}

Table 2: Asymptotic critical values for $R^{2}$ for different cases M1-M4. $\lambda$ denotes the relative breakpoint.

of our test proposal is not that straightforward. The $R^{2}$ is $o_{p}(1)$ only if $d_{x} \leq d_{y}$. We investigate these issues in the next section where we conduct an extensive simulation study on the empirical properties of the suggested test statistic.

\section{Monte Carlo study}

Our Monte Carlo study investigates the empirical size and power properties of the $R^{2}$ statistic under a variety of conditions.

\section{Empirical size}

We consider the following five different DGPs (M1-M5) under the null of a spurious relationship between $y_{t}$ and $x_{t}$. The following simple model is used for the data generation in case M1: $y_{t}=y_{t-1}+e_{t}$ and $x_{t}=x_{t-1}+v_{t}$. In case M2, we have: $y_{t}=\rho_{t} y_{t-1}+e_{t}, x_{t}=x_{t-1}+v_{t}$ with $\rho_{t}=1+D_{t}\left(\lambda_{y}\right)\left(\rho_{y}-1\right)$, $D_{t}\left(\lambda_{y}\right)=1\left(t / T>\lambda_{y}\right)$, and $\rho_{y} \in\{0.3,0.5,0.7\}$. The choice of $\rho_{y}$ corresponds to a strong, medium and mild 
reduction in persistence. The case M3 is analogous. In case M4, we have $y_{t}=\rho_{t} y_{t-1}+e_{t}, x_{t}=\phi_{t} x_{t-1}+v_{t}$, with $\rho_{t}$ as before, $\phi_{t}=1+D_{t}\left(\lambda_{x}\right)\left(\rho_{x}-1\right)$ and $D_{t}\left(\lambda_{x}\right)=1\left(t / T>\lambda_{x}\right)$. Lastly, case (M5) is specified as follows: $(1-L)^{d_{y}} y_{t}=e_{t},(1-L)^{d_{x}} x_{t}=v_{t}$, with $0.5<d_{y}, d_{x}<1$. The case of spurious regressions with fractionally integrated time series has been investigated, amongst others, by Marmol (1995), Marmol (1998), and Tsay and Chung (2000). The innovations are drawn from a bivariate standard Normal distribution with a diagonal covariance matrix. The number of replications equals 5,000 for each single experiment. We consider three different sample sizes: $T \in\{100,300,500\}$ which resemble situations where either quarterly or monthly recorded macroeconomic or financial data is analyzed. The breakpoints are located either in the beginning, in the middle or at the end of the sample, i.e. $\lambda_{y}, \lambda_{x} \in\{0.3,0.5,0.7\}$. The location of the breakpoints are treated as unknown and thus estimated from the data. For this purpose, we compare the experimental performance of three different breakpoint estimators which have been suggested in the related literature on changes in persistence, see Kim, Belaire Franch, and Badilli Amador (2002), Busetti and Taylor (2004) and Leybourne, Kim, and Taylor (2007). In particular, these estimators are given by,

$$
\begin{aligned}
\widehat{\lambda}_{K B A} & =\arg \max _{\tau} \frac{[(1-\tau) T]^{-2} S_{1}(\tau)}{[\tau T]^{-1} S_{0}(\tau)} \\
\widehat{\lambda}_{B T} & =\arg \max _{\tau} \frac{[(1-\tau) T]^{-2} S_{1}(\tau)}{[\tau T]^{-2} S_{0}(\tau)} \\
\hat{\lambda}_{L T K} & =\arg \min _{\tau}[\tau T]^{-2} S_{0}(\tau),
\end{aligned}
$$

with the sum-of-squares,

$$
\begin{aligned}
& S_{0}(\tau)=\sum_{t=1}^{[\tau T]}\left(z_{t}-\frac{1}{[\tau T]} \sum_{t=1}^{[\tau T]} z_{t}\right)^{2} \\
& S_{1}(\tau)=\sum_{t=1}^{[\tau T]}\left(z_{t}-\frac{1}{T-[\tau T]} \sum_{t=[\tau T]+1}^{T} z_{t}\right)^{2}
\end{aligned}
$$

defined for a time series $z_{t}$, see Hassler and Scheithauer (2011). The criterion functions are maximized (or minimized) over the interval $\tau \in[0.2,0.8]$ which is a common choice in practice. In case (M4), the minimum of $\widehat{\lambda}_{y}$ and $\widehat{\lambda}_{x}$ determine the critical values. Note that this follows from our theoretical results derived in Theorem 1 (iv).

The following null hypotheses of spurious regressions can be tested:

$$
\begin{array}{ll}
H_{0}^{(1)} & : \text { no persistence change in } y \text { and } x \\
H_{0}^{(2)} & : \text { persistence change in } y \\
H_{0}^{(3)} & : \text { persistence change in } x \\
H_{0}^{(4)} & : \text { persistence change in both, } y \text { and } x
\end{array}
$$

In practice, several situations may occur: (i) the user has some prior information or knowledge about the existence of a change in persistence, (ii) the user applies univariate pre-tests in order to investigate the 


\begin{tabular}{|c|c|c|c|c|c|c|c|}
\hline \multicolumn{2}{|l|}{ DGP } & \multicolumn{2}{|c|}{ M2 } & \multicolumn{2}{|c|}{ M3 } & \multicolumn{2}{|c|}{ M4 } \\
\hline$\lambda$ & $\rho$ & KBA & LTK & KBA & LTK & KBA & LTK \\
\hline \multicolumn{8}{|c|}{$H_{0}^{(2)}:$ persistence change in $y$} \\
\hline \multirow[t]{3}{*}{0.3} & 0.3 & 0.019 & 0.033 & 0.008 & 0.016 & 0.079 & 0.123 \\
\hline & 0.5 & 0.016 & 0.044 & 0.004 & 0.014 & 0.058 & 0.096 \\
\hline & 0.7 & 0.014 & 0.030 & 0.006 & 0.011 & 0.045 & 0.072 \\
\hline \multirow[t]{3}{*}{0.5} & 0.3 & 0.040 & 0.058 & 0.033 & 0.049 & 0.082 & 0.108 \\
\hline & 0.5 & 0.038 & 0.054 & 0.026 & 0.040 & 0.080 & 0.101 \\
\hline & 0.7 & 0.024 & 0.050 & 0.024 & 0.039 & 0.072 & 0.103 \\
\hline \multirow[t]{3}{*}{0.7} & 0.3 & 0.052 & 0.058 & 0.054 & 0.072 & 0.068 & 0.081 \\
\hline & 0.5 & 0.047 & 0.056 & 0.056 & 0.078 & 0.070 & 0.080 \\
\hline & 0.7 & 0.048 & 0.061 & 0.049 & 0.062 & 0.064 & 0.078 \\
\hline \multicolumn{8}{|c|}{$H_{0}^{(3)}$ : persistence change in $x$} \\
\hline \multirow[t]{3}{*}{0.3} & 0.3 & 0.008 & 0.014 & 0.026 & 0.041 & 0.096 & 0.127 \\
\hline & 0.5 & 0.008 & 0.016 & 0.018 & 0.038 & 0.069 & 0.104 \\
\hline & 0.7 & 0.003 & 0.005 & 0.010 & 0.022 & 0.038 & 0.062 \\
\hline \multirow[t]{3}{*}{0.5} & 0.3 & 0.029 & 0.048 & 0.033 & 0.054 & 0.080 & 0.099 \\
\hline & 0.5 & 0.031 & 0.045 & 0.035 & 0.052 & 0.072 & 0.102 \\
\hline & 0.7 & 0.028 & 0.042 & 0.032 & 0.058 & 0.069 & 0.100 \\
\hline \multirow[t]{3}{*}{0.7} & 0.3 & 0.058 & 0.074 & 0.048 & 0.054 & 0.073 & 0.084 \\
\hline & 0.5 & 0.060 & 0.075 & 0.045 & 0.054 & 0.078 & 0.090 \\
\hline & 0.7 & 0.048 & 0.068 & 0.055 & 0.066 & 0.072 & 0.082 \\
\hline \multicolumn{8}{|c|}{$H_{0}^{(4)}:$} \\
\hline \multirow[t]{3}{*}{0.3} & 0.3 & 0.000 & 0.000 & 0.000 & 0.000 & 0.001 & 0.002 \\
\hline & 0.5 & 0.000 & 0.001 & 0.000 & 0.000 & 0.001 & 0.004 \\
\hline & 0.7 & 0.000 & 0.000 & 0.000 & 0.000 & 0.000 & 0.001 \\
\hline \multirow[t]{3}{*}{0.5} & 0.3 & 0.008 & 0.006 & 0.010 & 0.004 & 0.028 & 0.022 \\
\hline & 0.5 & 0.009 & 0.005 & 0.010 & 0.006 & 0.022 & 0.016 \\
\hline & 0.7 & 0.006 & 0.004 & 0.009 & 0.008 & 0.015 & 0.007 \\
\hline \multirow[t]{4}{*}{0.7} & 0.3 & 0.028 & 0.020 & 0.028 & 0.014 & 0.040 & 0.028 \\
\hline & 0.5 & 0.031 & 0.020 & 0.029 & 0.018 & 0.036 & 0.026 \\
\hline & 0.7 & 0.025 & 0.016 & 0.024 & 0.014 & 0.035 & 0.024 \\
\hline & & $H_{0}^{(1)}$ & $H_{0}^{(2)}$ & $H_{0}^{(3)}$ & $H_{0}^{(4)}$ & & \\
\hline 1.0 & 1.0 & 0.052 & 0.047 & 0.048 & 0.032 & & \\
\hline
\end{tabular}

Table 3: Size results for $T=100$. The nominal significance level equals five percent. 


\begin{tabular}{ccccc}
\hline$\lambda$ & $\rho$ & M2 & M3 & M4 \\
\hline$H_{0}^{(1)}$ & : no persistence change in $y$ and $x$ \\
0.3 & 0.3 & 0.004 & 0.004 & 0.031 \\
& 0.5 & 0.004 & 0.005 & 0.020 \\
& 0.7 & 0.001 & 0.001 & 0.008 \\
0.5 & 0.3 & 0.026 & 0.036 & 0.065 \\
& 0.5 & 0.029 & 0.027 & 0.068 \\
& 0.7 & 0.020 & 0.026 & 0.050 \\
0.7 & 0.3 & 0.051 & 0.051 & 0.074 \\
& 0.5 & 0.053 & 0.050 & 0.070 \\
& 0.7 & 0.040 & 0.048 & 0.067 \\
\hline
\end{tabular}

Table 4: Size results for $T=100$ and the assumption of no breaks. The nominal significance level equals five percent.

empirical properties of the time series at hand, or (iii) the user decides and picks $H_{0}^{(4)}$ to ensure that no break is neglected. In our subsequent analysis, we will investigate whether it is harmful or even dangerous to select a null hypothesis which is not in line with the DGP (e.g. suppose that data is generated according to $H_{0}^{(2)}$, but the user tests instead either $H_{0}^{(1)}, H_{0}^{(3)}$ or $\left.H_{0}^{(4)}\right)$. This exercise can be seen as a robustness check for our suggested procedure ${ }^{7}$ It shall be noted that testing $H_{0}^{(1)}$ does not require breakpoint estimation as the limiting distribution is free of any nuisance parameters. When testing $H_{0}^{(2)}$ (or $H_{0}^{(3)}$ ) and $H_{0}^{(4)}$, breakpoint estimation becomes necessary as long as the breakpoint is treated as unknown, which seems most realistic for practical applications.

Simulation results for the least favorable sample size of $T=100$ are reported in Tables 3 and $44^{8}$ In Table 3, we consider correctly specified null hypotheses in the sense that the number of series with a break are corresponding to the data generating processes. We also investigate the consequences of mispecification. It appears that the $R^{2}$ test statistic performs very satisfactorily in small samples. We observe that the empirical significance level is in most cases close to the desired one of 5\%. Minor size distortions (in both directions) are likely to occur when the number of breaks under the null hypothesis is unequal to the true number of breaks. This means that when, for example $H_{0}^{(2)}$ is tested (rather than $H_{0}^{(4)}$ ), given that the data is generated according to model (M4), the test shows some upward size distortion. The magnitude of size distortions depends to some extent on the location of the breakpoint: The later the breakpoint, the milder is the distortion. In addition, it is interesting to note that the KBA breakpoint

\footnotetext{
${ }^{7}$ One may think of testing all four different null hypotheses with an appropriately adjusted significance level in order to deal with situation of multiple testing. This could be achieved by applying common procedures like the Bonferroni- or BenjaminiHochberg-type of corrections.

${ }^{8}$ Results for larger sample sizes are not reported to save space. Full results are available form the authors upon request. There is a general tendency that the performance of the test improves as the sample size increases (as to be expected).
} 
estimators offers the best test performance, closely followed by the LTK breakpoint estimator 9 We also consider the case M1, where no breaks occur, but the null hypothesis covers at least one series with a break (see the last line of Table 3). In this case, the test performs well. Only when two series with breaks are assumed, the test is slightly conservative.

Results in Table 4 show the empirical size for the case of testing $H_{0}^{(1)}$, i.e. no breaks are allowed for. Data is generated with a break in $y$ and/or in $x$. This kind of mispecification leads to some distortions: for an early breakpoint $(\lambda=0.3)$ the test is conservative, while it is correctly sized or liberal for late breaks, depending on whether only $y$ or $x$ exhibit a change in persistence or both of them. There is a slight tendency of the test to reject less often as $\rho$ increases.

We now turn to the results for fractionally integrated processes. In general, we find that the $R^{2}$ test behaves conservatively as indicated by empirical sizes near zero (unreported to save space). Thereby, we confirm the claims made in the previous section. In case of a spurious regression amongst fractionally integrated series, the test is likely to detect the spurious regression by rarely rejecting in favor of the alternative. This conclusion is not affected by the particular value of $d$.

\section{Empirical power}

The next step of our analysis deals with the empirical power of the $R^{2}$ test statistic. Under the alternative, $y_{t}$ and $x_{t}$ are dependent on each other and we consider Models 6 (constant persistence and cointegrated) and 7 (reduction in persistence at the same point in time; cointegrated in the first half of the sample and correlated in the second half). For model (M6), the DGP is given by: $y_{t}=\alpha+\beta x_{t}+e_{t}$, and $x_{t}=x_{t-1}+v_{t}$. Model (M7) reads in detail as follows: $y_{t}=\alpha+\beta x_{t}+u_{t}$, and $x_{t}=\phi_{t} x_{t-1}+v_{t}$, with $\phi_{t}=1+D_{t}\left(\lambda_{x}\right)\left(\rho_{x}-1\right)$. Again, $\rho_{x} \in\{0.3,0.5,0.7\}$ and $\lambda_{x} \in\{0.3,0.5,0.7\}$. We set $\alpha=\beta=1$. Results are reported in Table 5

The results reveal that the power in small samples is satisfying in most situations. But, the breakpoint influences the empirical power, which is not surprising as the critical values depend on the breakpoint (DGP: M7). The later the break is located in the sample, the easier is the detection of a meaningful relationship amongst the variables. The persistence parameter $\rho$ only plays a minor role in general, while higher power is found for early breaks when $\rho$ is relatively large. There are only minor differences between the breakpoint estimators. It can also be seen that it is costly in terms of power to test under the assumption of constant persistence when variables do in fact exhibits structural changes therein. Interestingly, the power of the test is relatively low when both breaks are taken into account. It appears that the test exhibits higher power when one assumes that only a single series has a break (instead of two). The reasons for this behaviour can be attributed to the minimum operator involved in the limit distribution of the $R^{2}$ and the performance of breakpoint estimators in small samples. The combination of both leads to relatively low values of $\lambda$ for which the test performs not as good as for large values of $\lambda$. Therefore, it can be beneficial in situations where the sample size is rather small to test either $H_{0}^{(2)}$ (or $H_{0}^{(3)}$ ) instead of $H_{0}^{(4)}$. Note that the test for $H_{0}^{(2)}$ (or $H_{0}^{(3)}$ ) does not suffer from being over-sized in this situation. The empirical power is nearly the same for $H_{0}^{(2)}$ and $H_{0}^{(3)}$ which is not surprising given the structure of the limit distributions, see

\footnotetext{
${ }^{9}$ Results for the BT estimator are omitted but available upon request. The reason for omission is its relatively poor performance.
} 


\begin{tabular}{rrrrrrrrr}
\hline DGP: M7 & \multicolumn{1}{c}{$H_{0}^{(1)}$} & \multicolumn{2}{c}{$H_{0}^{(2)}$} & \multicolumn{2}{c}{$H_{0}^{(3)}$} & \multicolumn{2}{c}{$H_{0}^{(4)}$} \\
$\lambda$ & $\rho$ & & KBA & LTK & KBA & LTK & KBA & LTK \\
\hline 0.3 & 0.3 & 0.154 & 0.364 & 0.402 & 0.333 & 0.385 & 0.055 & 0.068 \\
& 0.5 & 0.180 & 0.406 & 0.448 & 0.388 & 0.450 & 0.064 & 0.077 \\
& 0.7 & 0.204 & 0.523 & 0.582 & 0.484 & 0.530 & 0.074 & 0.088 \\
0.5 & 0.3 & 0.485 & 0.617 & 0.626 & 0.546 & 0.554 & 0.274 & 0.252 \\
& 0.5 & 0.486 & 0.656 & 0.673 & 0.583 & 0.600 & 0.304 & 0.276 \\
& 0.7 & 0.503 & 0.720 & 0.746 & 0.664 & 0.691 & 0.319 & 0.299 \\
0.7 & 0.3 & 0.699 & 0.767 & 0.768 & 0.742 & 0.719 & 0.529 & 0.492 \\
& 0.5 & 0.696 & 0.798 & 0.802 & 0.752 & 0.744 & 0.536 & 0.502 \\
& 0.7 & 0.720 & 0.818 & 0.840 & 0.802 & 0.806 & 0.547 & 0.518 \\
\hline DGP: M6 & & & & & & & & \\
1.0 & 1.0 & 0.853 & 0.946 & 0.966 & 0.908 & 0.937 & 0.721 & 0.700 \\
\hline
\end{tabular}

Table 5: Power results for $T=100$. The nominal significance level equals five percent.

Theorem 1. In case of constant persistence (DGP: M6), we find that power is generally higher than for changing persistence. Similar conclusions can be drawn as for M7.

\section{Empirical applications}

"The long-run Fisherian theory of interest states that a permanent shock to inflation will cause an equal change in the nominal interest rate so that the real interest rate is not affected by monetary shocks in the long run,.... If the nominal interest rate and the inflation rate are each integrated of order one, denoted $I(1)$, then the two variables should cointegrate with a slope coefficient of unity so that the real interest rate is covariance stationary" (Haug, Beyer, and Dewald 2011, p.1). As can be deducted from this paragraph, cointegration seems to be a natural testing strategy to verify empirically the validity of the Fisher hypothesis, or the Fisher effect.

Following the same lines, Phillips (2005) argues that this effect corresponds to the hypothesis that the real rate of interest is stationary. Furthermore, when the econometric analysis is carried out using expected inflation (as opposed to observed inflation), this effect implies that "the ex ante real rate of interest is stationary, so that, under rational expectations and stationary forecast errors for inflation, the Fisher effect implies a stationary ex post real rate of interest" Phillips (2005, p.132).

We collect data on interest rates, inflation and inflation expectations for Mexico and the US, to verify the Fisher hypothesis, not only under the traditional route of cointegration techniques, but also following the testing strategy suggested in this paper for the case when variables might be subject to changes in persistence.

The Mexican data set is built as follows. The inflation series we investigate $\left(\pi_{t}^{M}\right)$ are monthly, sea- 

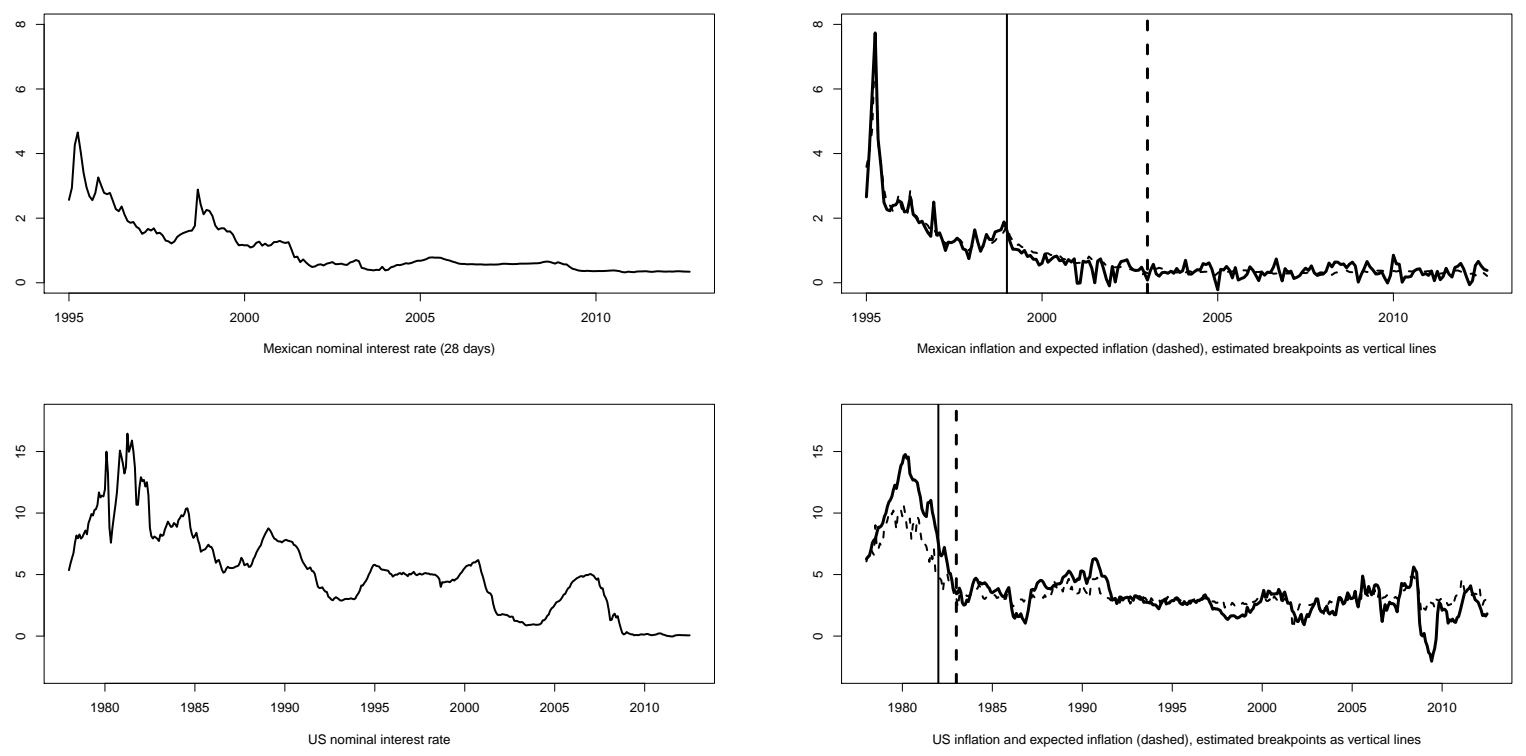

Figure 1: Time series under consideration.

sonally adjusted, based on the national index of consumer prices ${ }^{10}$ Inflation expectations $\left({ }^{e} \pi_{t}^{M}\right)$ are taken from the private sector survey of inflation expectations. ${ }^{11}$ The interest rates used are the Government Bonds, CETES at $28\left(i_{t}^{M 28}\right)$ and $91\left(i_{t}^{M 91}\right)$ days 12

For the US, inflation is calculated from the Consumer Price Index of All Urban Consumers (CPI) using the formula $100\left(C P I_{t}-C P I_{t-12} / C P I_{t-12}\right){ }_{13}^{13}$ Inflation expectations were obtained from the Federal Reserve Bank of St. Louis. The definition used is "Median expected price change next 12 months, Survey of Consumers" 14 The Three Months Treasury Bill was obtained from the Federal Reserve Bank of St. Louis 15

Anticipating the procedures and findings in this section, we first apply unit root test to verify the order of integration of individual variables. We find that variables follow a unit root process, according to several tests. Then we test for cointegration using the Johansen procedure. We find that there are either zero or two cointegrating vectors, this last finding contradicting our unit root results. Overall, cointegration techniques seem not to give empirical support to the Fisherian theory of interest rates for Mexico and the USA.

Given these results, we infer whether there have been any changes in persistence in the individual series using the approach of Leybourne, Kim, and Taylor (2007) (LKT in what follows), which allows

\footnotetext{
${ }^{10}$ Indice Nacional de Precios al Consumidor, INPC, obtained from the Banco de México at http://www.banxico.org.mx The inflation rate was calculated as $\pi_{t}^{M}=\left[\left(I N P C_{t}-I N P C_{t-1}\right) / I N P C_{t-1}\right] 100$.

${ }^{11}$ See Encuesta de Expectativas del Sector Privado, http://www.banxico.org.mx/estadisticas/index.html

${ }^{12}$ Bond rates were also obtained from Banco de Mexico as average rates in annual percentage points, and then converted to monthly percentages using the transformation $100[(1 / 12) \ln (1+$ annual\%CETE/100)].

${ }^{13}$ Bureau of Labor Statistics, at http://www.bls.gov/cpi/home.htm\#data.

${ }^{14}$ Available at http://research.stlouisfed.org/fred2/series/MICH

${ }^{15}$ Available at http://research.stlouisfed.org/fred2/series/TB3MS
} 
for multiples changes in persistence, and is robust to changes in the level of the variables. We find that for all series but the US interest rate, the $M$ test of LKT detects significant changes in persistence in the directions $I(1) \rightarrow I(0)$, that is, the series become stationary after the break.

Given that cointegration tests are built on the assumption that the series are $I(1)$ throughout, we cannot rely on these tests to verify the Fisher hypothesis (it is not known whether cointegration tests function properly under changes in persistence in the underlying variables). Therefore, we apply the procedure proposed in this paper; in particular, we use the $R^{2}$ in order to verify whether there is a long-run relationship between nominal interest rates and the inflation rate, using critical values provided in the paper (the asymptotic critical values for the cases M3 and M4 in Table 2).

\section{Tests for multiple changes in persistence}

We apply the so-called $M$ test, proposed by LKT, which allows to test for multiple changes in the order of integration of a time series. As discussed in Noriega and Ramos-Francia (2009), tests for a unit root, as the augmented Dickey-Fuller $(A D F)$ test, will not be consistent against processes which display changes in persistence, when applied to persistence change series, since the $I(1)$ part will dominate asymptotically. This argument also applies to tests for a single change in persistence, as those of Kim (2000) and Harvey, Leybourne, and Taylor (2006). Additionally, the LKT test allows consistent estimation of the change dates. We start by briefly presenting the basics of the LKT procedure, and after that we report the corresponding empirical results ${ }^{16}$ The $M$ test is based on doubly-recursive sequences of $D F$ type unit root statistics:

$$
M \equiv \inf _{\lambda \in(0,1) \tau \in(\lambda, 1)} \inf _{f} D F_{G}(\lambda, \tau)
$$

with corresponding estimators $(\hat{\lambda}, \hat{\tau}) \equiv \arg \inf _{\lambda \in(0,1)} \inf _{\tau \in(\lambda, 1)} D F_{G}(\lambda, \tau)$ for $\tau \in(\lambda, 1)$, and $\lambda \in(0,1)$, where $D F_{G}(\lambda, \tau)$ is obtained as the standard $t$-statistic associated with $\hat{\rho}_{i}$ in the fitted regression that uses the sample observations between $[\lambda T]$ and $[\tau T]$

$$
\Delta y_{t}^{d}=\hat{\rho}_{i} y_{t-1}^{d}+\sum_{j=1}^{k_{i}} \hat{b}_{i, j} \Delta y_{t-j}^{d}+\hat{\varepsilon}_{t}, \quad t=[\lambda T],[\lambda T+1], \ldots,[\tau T]
$$

where $y_{t}^{d} \equiv y_{t}-z_{t}^{\prime} \hat{\beta}$, with $\hat{\beta}$ the OLS estimate of $\beta$ obtained from regressing $y_{\lambda, T}$ on $z_{\lambda, T}$, where $y_{\lambda, T} \equiv$ $\left(y_{\lambda T}, y_{\lambda T+1}-\bar{\alpha} y_{\lambda T}, \ldots, y_{\tau T}-\bar{\alpha} y_{\tau T-1}\right)^{\prime}$ and $z_{\lambda, T} \equiv\left(z_{\lambda T}, z_{\lambda T+1}-\bar{\alpha} z_{\lambda T}, \ldots, z_{\tau T}-\bar{\alpha} z_{\tau T-1}\right)^{\prime}$, with $\bar{\alpha}=1+\bar{c} / T$, and $\bar{c}=-10$. In the empirical applications below, we set $\lambda=1 / T$ such that $\lambda T=1$. As in LKT, we use $\tau=0.20{ }^{17}$ For determining the value of $k_{i}$, we use the BIC for choosing the appropriate lag length for values of $k_{i}$ between 0 and 12, for every sample or sub-sample regression computed.

Following Noriega, Capistrán, and Ramos-Francia (2012), there are two hypotheses. The null, $H_{0}:$ the series is $I(1)$ throughout, and the alternative, $H_{1}$ : the series undergoes one or more regime shifts between $I(1)$ and $I(0)$ behavior. That is, under the alternative, the variable under study (inflation, expected inflation

\footnotetext{
${ }^{16}$ The presentation below heavily relies on Noriega, Capistrán, and Ramos-Francia (2012), from which further details can be obtained.

${ }^{17}$ As a robustness check in the empirical applications below, we used different values of $\tau$ and obtained qualitatively similar results.
} 


\begin{tabular}{lllcccc}
\hline & & & & & \multicolumn{2}{c}{ I(O) Periods } \\
Series & \multicolumn{2}{c}{ Sample } & $T$ & $M$ & Start & End \\
\hline${ }^{e} \pi_{t}^{M}$ & $1995: 01-$ & $2012: 09$ & 213 & $-5.36 * * *$ & $2003: 11$ & $2012: 09$ \\
$\pi_{t}^{M}$ & $1995: 01-$ & $2012: 09$ & 213 & $-7.34 * * *$ & $2002: 09$ & $2012: 09$ \\
$i_{t}^{M 28}$ & $1995: 01-$ & $2012: 09$ & 213 & $-4.14 * * *$ & $2004: 09$ & $2008: 05$ \\
& $2008: 06-$ & $2012: 09$ & 52 & $-5.48 * * *$ & $2009: 10$ & $2010: 12$ \\
& $2011: 01-$ & $2012: 09$ & 21 & $-7.00^{* *}$ & $2011: 05$ & $2012: 01$ \\
$i_{t}^{M 91}$ & $1995: 01-$ & $2012: 09$ & 213 & $-4.54 * * *$ & $2004: 08$ & $2008: 05$ \\
& $2008: 06-$ & $2012: 09$ & 52 & $-4.64 * * *$ & $2010: 12$ & $2012: 09$ \\
\hline${ }^{e} \pi_{t}^{U S}$ & $1978: 01-$ & $2012: 08$ & 415 & $-5.52 * * *$ & $1991: 08$ & $2007: 09$ \\
& $2007: 10-$ & $2012: 08$ & 58 & $-6.15 * * *$ & $2010: 11$ & $2012: 01$ \\
$\pi_{t}^{U S}$ & $1978: 01-$ & $2012: 08$ & 415 & $-4.67 * * *$ & $1991: 12$ & $2009: 01$ \\
$i_{t}^{U S 3 m}$ & $1978: 01-$ & $2012: 08$ & 415 & -3.26 & - & - \\
\hline
\end{tabular}

Table 6: Results of the LKT test for inflation and interest rate data; ***, and ** denote significance at the $1 \%$ and $5 \%$, respectively.

or the interest rate) is subject to $m \geq 1$ unknown persistence changes, giving rise to $m+1$ segments with change point fractions given by $\tau_{1}<\tau_{2}<\ldots<\tau_{m-1}<\tau_{m}$. Application of the $M$ test yields the start and end points of the first $I(0)$ regime over the whole sample. The presence of any further $I(0)$ regimes can be detected sequentially by applying the $M$ statistic to each of the resulting subintervals $[0, \hat{\lambda}]$ and $[\hat{\tau}, 1]$. Hence, the procedure partitions the data into separate $I(0)$ and $I(1)$ regimes.

We now turn to the application of the $M$ test of LKT to the interest rates and inflation data for Mexico and the US. Table 6 gathers the relevant results. The second column indicates the sample or subsample over which the $M$ test is applied. Column three indicates the available number of observation for the corresponding sample or subsample. In column $4, \widehat{k}_{i}$ indicates the estimated value of $k_{i}$ in $(5)$, while $M$ in column 5 indicates the estimated value of the test statistic in (4). The last two columns report the beginning and end of the $I(0)$ periods, identified by the procedure.

In order to show the use of Table 6 , let us begin with the case of the expected inflation for Mexico, ${ }^{e} \pi_{t}^{M}$. For this variable, the $M$ test is initially applied over the whole sample, 1995:01-2012:09, comprising 213 observations. As can be seen, the $M$ statistic rejects the null hypothesis that the series is $I(1)$ throughout, at the $1 \%$ level (the critical value taken from LKT is -4.536 , at the $1 \%$ level) ${ }^{18}$ The last column reports the period during which ${ }^{e} \pi_{t}^{M}$ behaved as an $I(0)$ variable: 2003:11-2012:09. This implies that the other part of the sample, 1995:01-2003:10, behaves as an I(1) variable. It is important to note that we also applied the LKT procedure over this last subsample, and found that the null could not be rejected (and therefore the result is not reported in Table 6). That is, for this first subsample, a unit root could not be rejected. A

\footnotetext{
${ }^{18}$ The critical values from LKT at the 10,5 , and $1 \%$, respectively, for sample sizes closest to those in column 3 of Table 6 are the following: For $T=400$ : $-3.627,-3.900,-4.438$; for $T=200:-3.662,-3.964,-4.536$; for $T=60$ : $-3.883,-4.240,-5.133$; for $T=50:-3.954,-4.351,-5.292$; and for $T=20:-4.736,-5.369,-7.530$.
} 
very similar interpretation can be made for $\pi_{t}^{M}$.

A more complex result is obtained for $i_{t}^{M 28}$, which presents three $I(0)$ periods: 2004:09-2008:05, 2009:10-2010:12, and 2011:05-2012:01. This can be generally interpreted as a series with $I(1)$ behaviour during the first part (1995:01-2004:08), and a stationary behaviour during the rest of time ${ }^{19}$ In fact, all four series for Mexico can be categorized as having undergone a change in persistence from $I(1)$ into $I(0)$ with the break occurring around the years 2002-2004 ${ }^{20}$

For the US, both inflation and inflation expectations behaved as $I(1)$ from the beginning of the sample (1978) through 1991, and $I(0)$ onwards -only interrupted towards the end of the sample by the financial crisis. (the date of the change in persistence does not coincide with the one in Noriega and Ramos-Francia (2009a), who used monthly instead of annual changes in prices). On the other hand, the three months Treasury Bill does not exhibit any change in persistence; it behaved as an I(1) variable throughout the sample period (the $M$ test did not detect any significant change in persistence from $I(1)$ to $I(0)$ ). This result is consistent with that found by LKT, which applied the $M$ test to monthly data on the log yields on 10 year Government bonds for the United States (among other countries), for the period 1978:1-2001:12. They also found the this yield is $I(1)$ throughout their sample.

The general conclusion is that, with the exception of $i_{t}^{U S 3 m}$, all variables have undergone a structural break in their stochastic behaviour, which might explain why we were not able to find cointegration between interest rates and inflation and, therefore, were unable to lend any empirical support to the Fisher hypothesis. From a different perspective, it can be argued that the presence of persistence change in the variables invalidates the use of cointegration techniques needed to verify the Fisher hypothesis, since cointegration necessitates (or assumes) the presence of stochastic trends in the individual variables throughout the sample period. To alleviate this problem, we present below an empirical strategy based on our asymptotic findings, in order to test for the validity of the Fisher hypothesis without resorting to cointegration techniques, using instead the $R^{2}$ statistic, as discussed in section 2 of the paper.

\section{Alternative approach to test the Fisher hypothesis}

Here we verify whether there can be found a long-run relationship between the nominal interest rate and the inflation rate for the US and Mexico by applying the approach advocated in this paper, that is, by using as a test statistic the coefficient of determination, $R^{2}$. We begin by estimating by OLS equation (4), which we reproduce here for convenience:

$$
y_{t+1}=a+\beta x_{t}+u_{t+1}, \quad t=1, \ldots T
$$

Table 7 below present results from the OLS estimation of this model for each pair of series. In the Table, $\widehat{\beta}$ is the OLS estimate of the slope parameter, $s_{\widehat{\beta}}$ is the estimated standard deviation of $\widehat{\beta}$; $p_{\beta=0}$ is the $p$-value of the null hypothesis $H_{0}: \beta=0$ using a $t$-test statistic, while $p_{\beta=1}$ is the $p$-value of the null hypothesis $H_{0}: \beta=1$. Finally, $R^{2}$ is the coefficient of determination which will be used to asses the validity of the Fisher hypothesis.

\footnotetext{
${ }^{19}$ The finding of three aparently separated $I(0)$ periods can be due to changes in the level of the series. See LKT for details.

${ }^{20}$ For the inflation series, the result is consistent with that found in Noriega, Capistrán, and Ramos-Francia (2012).
} 


\begin{tabular}{ccccccccccc}
\hline$y_{t+1}$ & $x_{t}$ & $\widehat{\beta}$ & $s_{\widehat{\beta}}$ & $p_{\beta=0}$ & $p_{\beta=1}$ & $R^{2}$ & $\widehat{\lambda}_{y, K B A}$ & $\widehat{\lambda}_{y, L T K}$ & $\widehat{\lambda}_{x, K B A}$ & $\widehat{\lambda}_{x, L T K}$ \\
\hline \multicolumn{10}{c}{ Mexico } \\
$i_{t+1}^{M 28}$ & $\pi_{t}^{M}$ & 0.771 & 0.026 & 0.000 & 0.000 & $0.805^{* * *}$ & 0.90 & 0.90 & 0.26 & 0.42 \\
$i_{t+1}^{M 91}$ & $\pi_{t}^{M}$ & 0.769 & 0.028 & 0.000 & 0.000 & $0.780^{* * *}$ & 0.90 & 0.90 & 0.26 & 0.42 \\
$i_{t+1}^{M 28}$ & ${ }^{e} \pi_{t}^{M}$ & 0.828 & 0.025 & 0.000 & 0.000 & $0.845^{* * *}$ & 0.90 & 0.90 & 0.48 & 0.48 \\
$i_{t+1}^{M 91}$ & ${ }^{e} \pi_{t}^{M}$ & 0.827 & 0.027 & 0.000 & 0.000 & $0.824^{* * *}$ & 0.90 & 0.90 & 0.48 & 0.48 \\
& & & & & United States & & & & \\
$i_{t+1}^{U S 3 m}$ & $\pi_{t}^{U S}$ & 0.897 & 0.040 & 0.000 & 0.011 & $0.547^{* * *}$ & 0.90 & 0.90 & 0.17 & 0.14 \\
$i_{t+1}^{U S 3 m}$ & ${ }^{e} \pi_{t}^{U S}$ & 1.250 & 0.074 & 0.000 & 0.001 & $0.409^{* *}$ & 0.90 & 0.90 & 0.17 & 0.14 \\
\hline
\end{tabular}

Table 7: Empirical results on the Fisher hypothesis

As can be seen from Table 7, for all regressions, we reject the hypothesis that the slope parameter is zero, but also reject that it is equal to one, at the 5\% level (but not at the $1 \%$ level for the case of the US for observed inflation). Note that these test decisions are based on standard asymptotic results which are likely to be invalid in this application.

Given our previous results on changes in persistence, we estimate the breakpoints by the KBA and the LTK estimator. When there is a single break in persistence, these estimators are more reliable than the segmentation procedure by LKT which allows for multiple changes in persistence. The relative breakpoint estimates are reported in the last four columns of Table 7. In contrast to the previous analysis, these results indicate a reduction on persistence for inflation only. For the interest rate series we find in all cases a value of 0.9 which is the upper bound of the interval of potential breakpoints. If actually no change in persistence occurs, but the breakpoint (which equals unity in this case) is still estimated, the breakpoint estimate is typically a corner solution as in our case. We deal with this ambiguity by testing both hypotheses, i.e. $H_{0}^{(3)}$ and $H_{0}^{(4)}$ for the Mexican case. For the US, we test $H_{0}^{(3)}$ which is in accordance with the previous analysis and the breakpoint estimates reported in Table 7 . The breakpoint estimates themselves are interesting in their own right: For Mexico, the estimated break dates are July $1999(\lambda=0.26)$, June $2002(\lambda=0.42)$ and July $2003(\lambda=0.48)$. Note that for expected inflation, both estimators (KBA and LTK) yield exactly the same result. For the US, the estimated break dates are October $1982(\lambda=0.14)$ and September 1983 $(\lambda=0.17)$. These estimates are in line with findings in many related studies.

The $R^{2}$ statistics are quite high for Mexico, while they are much lower for the US. We compare the various $R^{2}$ statistics in Table 7 to the relevant critical values in Table 2 . For Mexico, the Fisher hypothesis holds in all cases when testing $H_{0}^{(3)}$ as the $R^{2}$ is highly significant (at the nominal significance level of one percent). Results are robust with respect to the choice of the breakpoint estimator. When testing $H_{0}^{(4)}$, meaning that both series are allowed to exhibit a change in persistence and not only the inflation series, then the evidence is weaker, but still rejecting the null hypothesis of a spurious regression in all cases at least at the nominal ten percent level of significance. In general, evidence is somewhat stronger when expected inflation is used. In this case, the $R^{2}$ statistic is significant at the five percent level. 
Results for the US indicate clear rejections of the null hypothesis, too. When using the actual inflation series, the null hypothesis is rejected at the one percent level. Evidence is a bit lower when expected inflation is used, contrary to the Mexican case. Results are robust with respect to the particular breakpoint estimator in use.

\section{Concluding remarks}

The contribution of this paper is threefold: (i) We extend the results within the spurious inference literature by studying the estimates of a regression under shifting persistence variables. The results of such an extension are in line with (and similar to) those related to independent and integrated to the order one variables studied by Phillips in the late Eighties. (ii) We propose a test procedure that distinguishes between spurious regressions and genuine ones, something that cannot be done, neither by cointegration analysis (when the variables are not known to exhibit a change in persistence), nor by classical statistical inference, chiefly $t$ - and $\mathcal{F}$ - test statistics. Monte Carlo experiments demonstrate that the test performs well in small samples, and when the breakpoints are unknown, both under the null and the alternative. Moreover, it is quite robust to mispecification of the number of series with breaks which is encouraging for applied work. (iii) We apply our test statistic to the Fisher hypothesis for the U.S. and the Mexican case. Contrary to the usual rejection of the hypothesis (using cointegration techniques), our test offers strong evidence concerning the validity of the Fisher hypothesis.

\section{References}

BARSKY, R. B. (1987): "The Fisher hypothesis and the forecastability and persistence of inflation," Journal of Monetary Economics, 19(1), 3-24.

BUSETTI, F., AND A. TAYLOR (2004): “Tests of stationarity against a change in persistence," Journal of Econometrics, 123(1), 33-66.

Christopoulos, D. K., And M. A. León-Ledesma (2007): “A Long-Run Non-Linear Approach to the Fisher Effect," Journal of Money, Credit and Banking, 39(2-3), 543-559.

Entorf, H. (1997): "Random Walks With Drifts: Nonsense Regression and Spurious Fixed-Effect Estimation," Journal of Econometrics, 80, 287-296.

Garcia, R., And P. Perron (1996): “An Analysis of the Real Interest Rate Under Regime Shifts," The Review of Economics and Statistics, 78(1), 111-125.

Granger, C., N. Hyung, And Y. JEON (2001): “Spurious regressions with stationary series,” Applied Economics, 33(7), 899-904.

Granger, C., And P. Newbold (1974): "Spurious Regressions in Econometrics," Journal of Econometrics, 2, 11-20. 
Halunga, A., D. R. Osborn, And M. Sensier (2008): "Changes in the order of integration of US and UK inflation," Economics Letters, 102, 30-32.

Harvey, D., S. Leybourne, And A. TAylor (2006): "Modified tests for a change in persistence," Journal of Econometrics, 134(2), 441-469.

Hassler, U., And J. Scheithauer (2011): “Detecting changes from short to long memory," Statistical Papers, 52, 847-870.

Haug, A., A. Beyer, And W. Dewald (2011): "Structural Breaks and the Fisher Effect," The BE Journal of Macroeconomics, 11(1).

Jensen, M. J. (2009): “The Long-Run Fisher Effect: Can It Be Tested?,” Journal of Money, Credit and Banking, 41(1), 221-231.

KanG, K. H., C.-J. Kim, And J. Morley (2009): “Changes in US inflation persistence,” Studies in Nonlinear Dynamics \& Econometrics, 13(4), 1-21.

KeJRiwal, M. (2012): “The Nature of Persistence in Euro Area Inflation: A Reconsideration,” mimeo.

KIM, J. (2000): “Detection of change in persistence of a linear time series," Journal of Econometrics, 95(1), 97-116.

Kim, J., J. Belaire Franch, and R. Badilli Amador (2002): "Corrigendum to Detection of Change in Persistence of a Linear Time Series," Journal of Econometrics, 109, 389-392.

Kouretas, G. P., And M. E. Wohar (2012): "The dynamics of inflation: a study of a large number of countries," Applied Economics, 44(16), 2001-2026.

Koustas, Z., AND A. Serletis (1999): “On the Fisher effect,” Journal of Monetary Economics, 44(1), $105-130$.

Kumar, M. S., And T. OKimoto (2007): "Dynamics of persistence in international inflation rates," Journal of Money, Credit and Banking, 39(6), 1457-1479.

Kurozumi, E. (2005): "Detection of Structural Change in the Long-run Persistence in a Univariate Time Series," Oxford Bulletin of Economics and Statistics, 67(2), 181-206.

LAI, K. S. (2008): "The puzzling unit root in the real interest rate and its inconsistency with intertemporal consumption behavior," Journal of International Money and Finance, 27(1), 140-155.

LANNE, M. (2006): "Nonlinear dynamics of interest rate and inflation,” Journal of Applied Econometrics, 21(8), 1157-1168.

Leybourne, S., T. Kim, And A. TAYlor (2007): “Detecting multiple changes in persistence," Studies in Nonlinear Dynamics \& Econometrics, 11(3), 1370-1370. 
Leybourne, S., T.-H. Kim, V. Smith, and P. Newbold (2003): "Tests for a change in persistence against the null of difference-stationarity," The Econometrics Journal, 6(2), 291-311.

Leybourne, S., R. TAYlor, And T.-H. Kim (2007): "CUSUM of Squares-Based Tests for a Change in Persistence," Journal of Time Series Analysis, 28(3), 408-433.

Malliaropulos, D. (2000): "A note on nonstationarity, structural breaks, and the Fisher effect," Journal of Banking \& Finance, 24(5), 695-707.

Marmol, F. (1995): "Spurious Regressions Between I(d) Processes," Journal of Time Series Analysis, $16,313-321$.

Marmol, F. (1996): “Nonsense Regressions between Integrated Processes of Different Orders.," Oxford Bulletin of Economics \& Statistics, 58(3), 525-36.

Marmol, F. (1998): "Spurious Regression Theory with Nonstationary Fractionally Integrated Processes," Journal of Econometrics, 84, 233-250.

NeEly, C. J., And D. E. RAPACH (2008): "Real interest rate persistence: evidence and implications," Federal Reserve Bank of St. Louis Working Paper Series.

Noriega, A., C. Capistrán, and M. Ramos-Francia (2012): “On the dynamics of inflation persistence around the world," Empirical Economics, pp. 1-23.

Noriega, A., And M. RAmos-Francia (2009): “The dynamics of persistence in US inflation,” Economics Letters, 105(2), 168-172.

Noriega, A., And D. Ventosa-Santaulària (2007): "Spurious Regression And Trending Variables," Oxford Bulletin of Economics and Statistics, 7, 4-7.

O’Reilly, G., And K. Whelan (2005): "Has euro-area inflation persistence changed over time?, Review of Economics and Statistics, 87(4), 709-720.

Perron, P. (2006): “Dealing with structural breaks," Palgrave Handbook of Econometrics, 1, 278-352.

PhIlliPs, P. (1986): “Understanding Spurious Regressions in Econometrics,” Journal of Econometrics, $33,311-340$.

- (2005): “Econometric analysis of Fisher's equation,” American Journal of Economics and Sociology, 64(1), 125-168.

RAPACH, D. E., AND C. E. WEBER (2004): "Are real interest rates really nonstationary? New evidence from tests with good size and power," Journal of Macroeconomics, 26(3), 409-430.

RAPACH, D. E., AND M. E. WohaR (2005): "Regime changes in international real interest rates: Are they a monetary phenomenon?," Journal of Money, Credit, and Banking, 37(5), 887-906. 
Rose, A. K. (1988): "Is the real interest rate stable?," The Journal of Finance, 43(5), 1095-1112.

TSAY, W., AND C. CHUng (2000): “The spurious regression of fractionally integrated processes,” Journal of Econometrics, 96(1), 155-182.

TsonG, C.-C., AND C.-F. LEE (2013): "Quantile cointegration analysis of the Fisher hypothesis," Journal of Macroeconomics, 35, 186-198.

Ventosa-S Antaulària, D. (2009): “Spurious regression,” Journal of Probability and Statistics, 2009, $1-27$.

Westerlund, J. (2008): "Panel cointegration tests of the Fisher effect," Journal of Applied Econometrics, 23(2), 193-233.

\section{A Asymptotic calculations}

We present the proof for case M4. All the remaining cases follow the same steps. Let $x_{t}$ and $y_{t+1}$ be generated by eqs. (2) and (3), where, $\delta=0$ and $\phi=1$ for $t=1,2, \ldots,\left[\lambda_{x} T\right]$ and $\delta \neq 0$ and $|\phi|<1$ for $t=\left[\lambda_{x} T\right]+1, \ldots, T, \lambda_{x} \in[0,1] .\left[\lambda_{x} T\right]$ denotes the non-null integer of $\lambda_{x} T$. By solving these equations recursively, you get,

$$
\begin{aligned}
x_{t} & =\left(\xi_{x, t-1}+v_{t}\right) \mathbf{I}_{\mathbf{x}}\left(\mathbf{t} \leq\left[\lambda_{\mathbf{x}} \mathbf{T}\right]\right)+\left(\boldsymbol{\delta}^{*}+e_{t}\right)\left[1-\mathbf{I}_{\mathbf{x}}\left(\mathbf{t} \leq\left[\lambda_{\mathbf{x}} \mathbf{T}\right]\right)\right], \\
y_{t+1} & =\left(\xi_{y, t}+e_{t+1}\right) \mathbf{I}_{\mathbf{y}}\left(\mathbf{t} \leq\left[\lambda_{\mathbf{y}} \mathbf{T}\right]\right)+\left(\mu^{*}+\varepsilon_{t+1}\right)\left[1-\mathbf{I}_{\mathbf{y}}\left(\mathbf{t} \leq\left[\lambda_{\mathbf{y}} \mathbf{T}\right]\right)\right],
\end{aligned}
$$

where, $\delta^{*}=\delta /(1-\phi), \mu^{*}=\mu /(1-\rho), e_{t}=(1-\phi L)^{-1} v_{t}, \varepsilon_{t+1}=(1-\rho L)^{-1} e_{t+1}, \xi_{x, t}=\sum_{i=1}^{t} v_{i}, \xi_{y, t+1}=$ $\sum_{i=1}^{t+1} e_{i}$, and $\mathbf{I}_{\mathbf{x}}(\cdot)$ and $\mathbf{I}_{\mathbf{y}}(\cdot)$ are indicator functions. The asymptotics of the $R^{2}$ requires several prior asymptotics results for the following objects: $R^{2}=1-\sum \hat{u}_{t+1}^{2} / \sum\left(y_{t+1}-\bar{y}\right)^{2} ; \sum \hat{u}_{t}^{2}=\sum y_{t+1}^{2}+\hat{\alpha}^{2} T+$ $\hat{\beta}^{2} \sum x_{t}^{2}-2 \hat{\alpha} \sum y_{t+1}-2 \hat{\beta} \sum y_{t+1} x_{t}+2 \hat{\alpha} \hat{\beta} \sum x_{t} ; \underline{\beta} \stackrel{\text { def }}{=}(\hat{\alpha} \hat{\beta})^{\prime}=\left(X^{\prime} X\right)^{-1} X y$, where $X=\left(x_{1} \ldots x_{T}\right)^{\prime}$ and $y=$ $\left(y_{2} \ldots y_{T+1}\right)^{\prime}$. The asymptotic properties of all the elements that appear on these expressions are wellknown (see (Phillips 1986), for instance):

$$
\begin{aligned}
T^{-\frac{3}{2}} \sum x_{t} & \stackrel{D}{\rightarrow} \int_{0}^{\lambda_{x}} W_{x} \\
T^{-\frac{3}{2}} \sum y_{t+1} & \stackrel{D}{\rightarrow} \int_{0}^{\lambda_{y}} W_{y} \\
T^{-2} \sum x_{t}^{2} & \stackrel{D}{\rightarrow} \int_{0}^{\lambda_{x}}\left(W_{x}\right)^{2} \\
T^{-2} \sum y_{t+1}^{2} & \stackrel{D}{\rightarrow} \int_{0}^{\lambda_{y}}\left(W_{y}\right)^{2} \\
T^{-2} \sum x_{t} y_{t+1} & \stackrel{D}{\rightarrow} \int_{0}^{\lambda_{I}} W_{x} W_{y}
\end{aligned}
$$


where $\lambda_{I}=\min \left(\lambda_{x}, \lambda_{y}\right)$. The remaining calculi, that is, replacing eqs. 6.10 in the formula of $\hat{\alpha}, \hat{\beta}, \sum \hat{u}_{t}^{2}$, and $R^{2}$, is straightforward, but cumbersome and tedious. The above expressions are equivalent to those presented in Phillips (1987); they only differ in the upper limit of the stochastic integrals $\left(\lambda_{x} / \lambda_{x} / \lambda_{I}\right.$ instead of 1); therefore, the asymptotic expressions of the $R^{2}$ vary in exactly the same manner. This statement can be easily proved by obtaining the limit expressions using Mathematica ${ }^{T M}$. The Mathematica code is available upon request. 
2012-52: $\quad$ José Manuel Corcuera, Emil Hedevang, Mikko S. Pakkanen and Mark Podolskij: Asymptotic theory for Brownian semi-stationary processes with application to turbulence

2012-53: Rasmus Søndergaard Pedersen and Anders Rahbek: Multivariate Variance Targeting in the BEKK-GARCH Model

2012-54: $\quad$ Matthew T. Holt and Timo Teräsvirta: Global Hemispheric Temperature Trends and Co-Shifting: A Shifting Mean Vector Autoregressive Analysis

2012-55: Daniel J. Nordman, Helle Bunzel and Soumendra N. Lahiri: A Non-standard Empirical Likelihood for Time Series

2012-56: $\quad$ Robert F. Engle, Martin Klint Hansen and Asger Lunde: And Now, The Rest of the News: Volatility and Firm Specific News Arrival

2012-57: Jean Jacod and Mark Podolskij: A test for the rank of the volatility process: the random perturbation approach

2012-58: Tom Engsted and Thomas Q. Pedersen: Predicting returns and rent growth in the housing market using the rent-to-price ratio: Evidence from the OECD countries

2013-01: $\quad$ Mikko S. Pakkanen: Limit theorems for power variations of ambit fields driven by white noise

2013-02: Almut E. D. Veraart and Luitgard A. M. Veraart: Risk premia in energy markets

2013-03: $\quad$ Stefano Grassi and Paolo Santucci de Magistris: It's all about volatility (of volatility): evidence from a two-factor stochastic volatility model

2013-04: Tom Engsted and Thomas Q. Pedersen: Housing market volatility in the OECD area: Evidence from VAR based return decompositions

2013-05: Søren Johansen and Bent Nielsen: Asymptotic analysis of the Forward Search

2013-06: Debopam Bhattacharya, Pascaline Dupasand Shin Kanaya: Estimating the Impact of Means-tested Subsidies under Treatment Externalities with Application to Anti-Malarial Bednets

2013-07: $\quad$ Sílvia Gonçalves, Ulrich Hounyo and Nour Meddahi: Bootstrap inference for pre-averaged realized volatility based on non-overlapping returns

2013-08: Katarzyna Lasak and Carlos Velasco: Fractional cointegration rank estimation

2013-09: Roberto Casarin, Stefano Grassi, Francesco Ravazzolo and Herman K. van Dijk: Parallel Sequential Monte Carlo for Efficient Density Combination: The Deco Matlab Toolbox

2013-10: Hendrik Kaufmann and Robinson Kruse: Bias-corrected estimation in potentially mildly explosive autoregressive models

2013-11: $\quad$ Robinson Kruse, Daniel Ventosa-Santaulària and Antonio E. Noriega: Changes in persistence, spurious regressions and the Fisher hypothesis 